\title{
TRABALHO DOMÉSTICO: DESAFIOS PARA O TRABALHO DECENTE
}

\author{
SOLANGE SANCHES \\ Organização das Nações Unidas para a Agricultura e a Alimentação \\ Organização Internacional do Trabalho
}

\begin{abstract}
Resumo: Este artigo apresenta um panorama da situação das trabalhadoras domésticas e traz algumas questões relativas à sua dimensão no mundo e no Brasil, suas condições de trabalho e importância para o funcionamento geral dos mercados de trabalho e dos domicílios. Buscase mostrar a relevância que tem o conceito de trabalho decente, promovido pela Organização Internacional do Trabalho (OIT), para o trabalho doméstico e a equiparação de seus direitos no trabalho aos do conjunto das trabalhadoras e dos trabalhadores. Ressalta-se a oportunidade da discussão na próxima Conferência Internacional do Irabalho da OIT, em 2010, na qual o tema é ponto de pauta com vistas à elaboração de um instrumento internacional de proteção ao trabalho doméstico.
\end{abstract}

Palavras-chave: trabalho doméstico; trabalho decente; condições de trabalho; gênero; igualdade.

\section{Introdução}

O trabalho doméstico remunerado é uma das atividades para as quais a noção de trabalho decente' tem especial importância e, com certeza, está entre aquelas para as quais construir condições para um trabalho decente constitui um dos maiores desafios. ${ }^{2}$ Transformar a situação atual das trabalhadoras domésticas em todo o mundo significa ultrapassar incontáveis preconceitos, estereótipos e discriminações que pesam sobre essa atividade, que são fruto de heranças históricas do patriarcalismo, da servidão e da escravatura e que se reconstruíram, de outras formas, nas sociedades capitalistas modernas. Como aponta a OIT, o trabalho doméstico, "nas suas manifestações contemporâneas, é um

\footnotetext{
Copyright (c) 2009 by Revista Estudos Feministas.

${ }^{1}$ Trabalho decente é qualquer ocupação produtiva adequadamente remunerada e exercida em condições de liberdade, equidade e segurança e que seja capaz de garantir uma vida digna para as pessoas (ORGANIZAÇÃO INTERNACIONAL DO TRABALHO, 2007).

${ }^{2}$ No momento da elaboração do texto, a pesquisadora trabalhava na Organização Internacional do Trabalho (OIT), no Brasil. Agora é consultora da Organização das Nações Unidas para a Agricultura e a Alimentação (FAO) e da OIT em Santiago do Chile.
} 
fenômeno mundial que perpetua as hierarquias baseadas em raça, na origem étnica, em pertencer a um grupo autóctone, em casta e na nacionalidade". ${ }^{3}$

O que é o trabalho doméstico? Ele refere-se aos afazeres realizados por uma pessoa em troca de remuneração (em dinheiro ou espécie, como ainda é corrente em várias partes do mundo). Esses afazeres compreendem o cuidado com o lar, o que envolve a realização de um grande e variado conjunto de atividades: serviços de limpeza, arrumação, cozinha, cuidado das roupas e outros itens de vestuário, e, em muitos casos, cuidado de crianças, idosos ou mesmo plantas e animais domésticos. A Classificação Brasileira de Ocupações (CBO) apresenta a extensa lista das tarefas relacionadas ao trabalho doméstico nas suas várias modalidades. ${ }^{4}$

A legislação brasileira, de forma semelhante a muitos países no mundo, define o trabalho doméstico remunerado como aquele "realizado por pessoa maior de 16 anos que presta serviços de natureza contínua (frequente, constante) e de finalidade não-lucrativa à pessoa ou à família, no âmbito residencial destas". ${ }^{5}$ Compõem a categoria, na legislação brasileira, as pessoas que trabalham como

cozinheiro(a), governanta, babá, lavadeira, faxineiro(a), vigia, motorista particular, jardineiro(a), acompanhante de idosos(as), entre outras. O(a) caseiro(a) também é considerado(a) empregado(a) doméstico(a), quando o sítio ou local onde exerce a sua atividade não possui finalidade lucrativa.

Os/as trabalhadores/as domésticos/as são uma parcela expressiva da força de trabalho no mundo. Segundo a OIT, estimativas conservadoras apontam mais de 100 milhões de pessoas, ${ }^{7}$ que representam entre $4 \%$ até $10 \%$ da ocupação total (feminina e masculina) nos países em desenvolvimento e cerca de $1 \%$ a 2,5\% nos países desenvolvidos. Na América Latina, o trabalho doméstico conta com aproximadamente 12 milhões de pessoas e representa $14 \%$ da ocupação feminina na região. ${ }^{8} \mathrm{E}$, em todo mundo, embora os homens ocupem funções como faxineiros, motoristas ou jardineiros, as mulheres são sempre a imensa maioria no trabalho doméstico, conforme se pode observar nos dados da Tabela $1 .{ }^{9}$

A ocupação no trabalho doméstico continua em nível elevado não somente nos países em desenvolvimento, mas inclusive nos países desenvolvidos. Do ponto de vista da demanda por esse serviço, vêm concorrendo para isso mudanças na organização e na intensificação do trabalho, diminuição do gasto públiço com serviços sociais, envelhecimento das populações e falta de políticas de conciliação entre trabalho e responsabilidades familiares.

Do ponto de vista da oferta, o aumento da desigualdade e da pobreza levou muitas mulheres à atividade remunerada, assim como à recente feminização da migração internacional. O trabalho doméstico mantém-se, particularmente nas situações de crise e nos mercados de trabalho desestruturados e com escassa oferta de postos, como uma importante porta de entrada para as jovens de menores rendimentos. Nas últimas décadas, o crescimento da participação das mulheres em todos os segmentos no mercado de trabalho é um fato mais tradicionalmente reservado às mulheres e também nos mais refratários,

\footnotetext{
${ }^{3}$ ORGANIZAÇÃO INTERNACIONAL DO TRABALHO, 2009, p. 5, tradução nossa.

${ }^{4}$ Solange SANCHES, 2006.

${ }^{5}$ MINISTÉRIO DO TRABALHO E EMPREGO, 2009.

${ }^{6}$ MINISTÉRIO DO TRABALHO E EMPREGO, 2009.

7 ORGANIZAÇÃO INTERNACIONAL DO TRABALHO, 2008.

${ }^{8}$ ORGANIZAÇÃO INTERNACIONAL DO TRABALHO E PROGRAMA DAS NAÇÕES UNIDAS PARA O DESENVOLVIMENTO, 2009.

${ }^{9}$ ORGANIZAÇÃO INTERNACIONAL DO TRABALHO, 2009, p. 6, tradução nossa.
} 


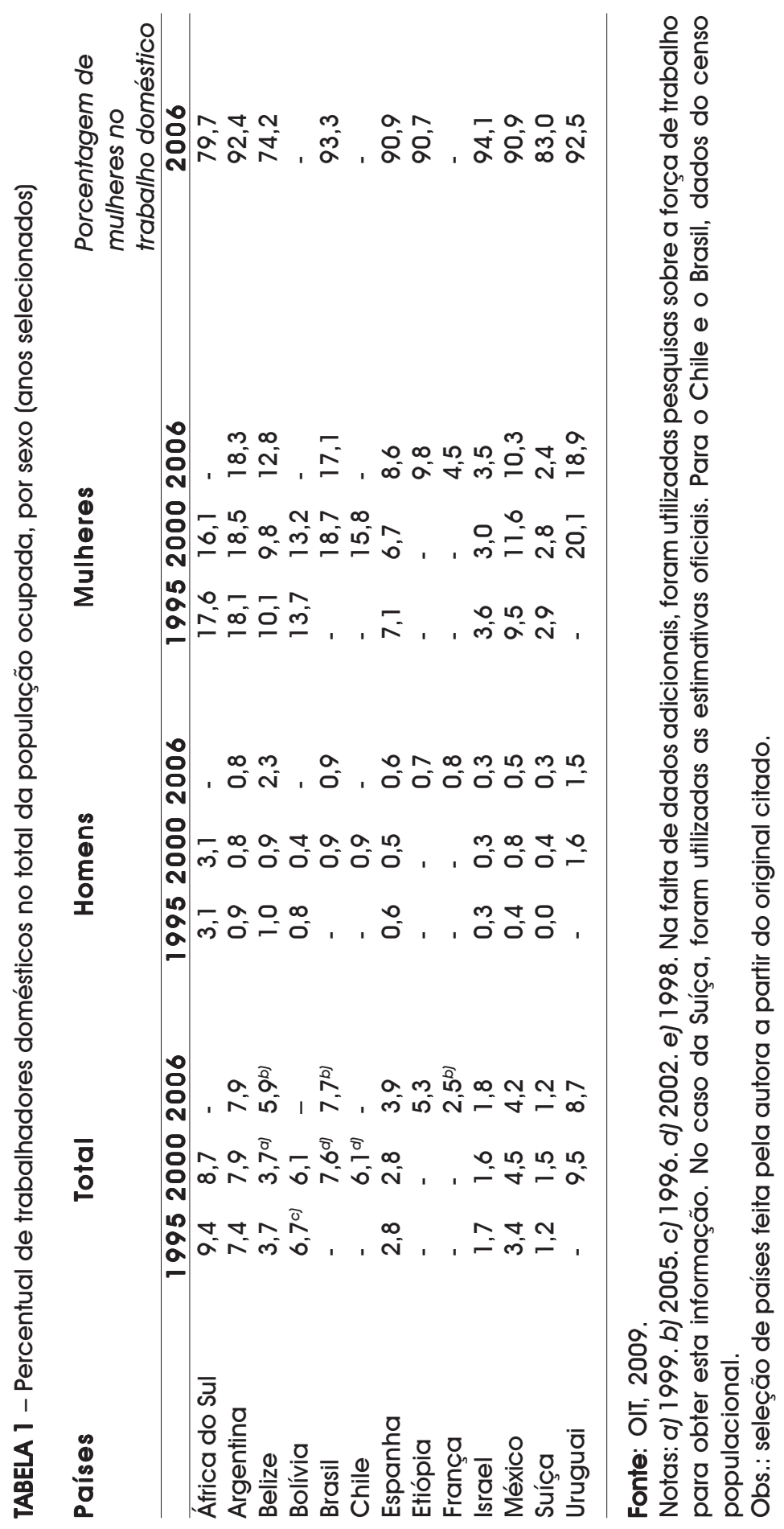


como certos setores da indústria, da produção científica ou da construção civil. Nesse período, o trabalho doméstico continuou a desempenhar um papel relevante na ocupação feminina, mantendo-se entre as principais categorias ocupacionais das mulheres no mundo.

No Brasil, em 2007, o trabalho doméstico remunerado empregava 6.731.197 pessoas, das quais $94 \%$ eram mulheres, segundo dados da Pesquisa Nacional por Amostra de Domicílios (PNAD) do IBGE, apresentados pelo Retrato das desigualdades. ${ }^{10}$ Destas mulheres, $61 \%$ eram negras e $39 \%$, brancas. É a principal ocupação feminina, respondendo por $16,4 \%$ do trabalho das mulheres, e é especialmente importante para as mulheres negras: $21,4 \%$ delas trabalham como domésticas em comparação a $12,1 \%$ entre as mulheres brancas. Da mesma forma que no restante do mundo, o trabalho doméstico no Brasil significa somente $0,8 \%$ da ocupação entre os homens.

O trabalho doméstico está, no entanto, entre as ocupações mais precárias, com níveis de remuneração muito baixos, com más condições de trabalho e altos riscos à saúde e à integridade física das trabalhadoras. Além disso, não somente no Brasil, mas na maioria dos países, os direitos das trabalhadoras domésticas não são equivalentes aos direitos do conjunto dos trabalhadores e, ainda assim, não são cumpridos.

TABELA 2 - Salário mínimo e rendimentos do trabalho doméstico feminino, segundo cor/ raça - Brasil 1996-2007

\begin{tabular}{c|ccc|c}
\hline $\begin{array}{c}\text { Rendimento real mensal da } \\
\text { ocupação principal }\end{array}$ & \multicolumn{2}{|c|}{ Renda média mensal (em R\$) } & $\begin{array}{l}\text { Rendimento das } \\
\text { domésticas sobre } \\
\text { o rendimento dos } \\
\text { ocupados }\end{array}$ \\
\hline $\begin{array}{c}\text { Rendimento dos ocupados } \\
\text { Das trabalhadoras domésticas }\end{array}$ & 1996 & 2007 & $\%$ & $\%$ \\
trabalhadoras domésticas & 301,79 & 329,87 & 9,31 & 40,2 \\
$\quad \begin{array}{c}\text { brancas } \\
\text { trabalhadoras domésticas } \\
\text { negras }\end{array}$ & 329,39 & 355,65 & 7,97 & 43,3 \\
Salário mínimo real & 279,19 & 313,34 & 12,23 & 38,2 \\
\hline
\end{tabular}

Fonte: Adaptado de: IBGE e PNAD apud PINHEIRO et al., 2008.

Elaborado pela autora.

Os rendimentos das trabalhadoras domésticas, no Brasil, equivaliam a apenas $40 \%$ da média dos rendimentos de todas as pessoas que tinham uma ocupação em 2007. Na comparação, as trabalhadoras domésticas negras recebiam ainda menos: somente $38 \%$ da média dos ocupados do país. Para o conjunto das domésticas, os rendimentos situamse muito próximos ao salário mínimo, como mostra a Tabela 2, por isso as domésticas constituem uma das categorias para as quais a recuperação do poder de compra do mínimo ocorrida nos últimos anos teve importância crucial na elevação e na manutenção de seu poder aquisitivo, bem como na superação da situação de pobreza de suas famílias.

\footnotetext{
${ }^{10}$ Luana PINHEIRO et al., 2008.
} 
TABELA 3 - Trabalhadoras domésticas com carteira de trabalho assinada, segundo cor/ raça - Brasil 1996-2007

\begin{tabular}{llll} 
Ano & Negra & Branca & Total \\
\hline 1996 & 18,7 & 23,6 & 20,9 \\
1997 & 19,0 & 24,8 & 21,6 \\
1998 & 21,9 & 25,5 & 23,4 \\
1999 & 21,2 & 26,9 & 23,7 \\
2001 & 22,7 & 27,8 & 25,0 \\
2002 & 21,3 & 29,0 & 24,7 \\
2003 & 23,4 & 29,9 & 26,1 \\
2004 & 22,0 & 28,6 & 24,9 \\
2005 & 23,7 & 27,8 & 25,3 \\
2006 & 23,9 & 30,2 & 26,4 \\
2007 & 25,2 & 30,5 & 27,2 \\
\hline
\end{tabular}

Fonte: Adaptado de: IBGE e PNAD apud PINHEIRO et al., 2008.

Elaborado pela autora.

Embora apresente crescimento constante desde os anos 1990, o percentual de trabalhadoras domésticas com carteira de trabalho assinada ainda estava atingindo os $30 \%$ para as mulheres brancas, e para as negras esse percentual ainda se situava em 25,2\% em 2007 (ver Tabela 3). Essa situação, aliada à baixa contribuição previdenciária das domésticas que trabalham como autônomas, ${ }^{11}$ reforça a desproteção social em que vivem essas trabalhadoras.

De forma geral, as trabalhadoras domésticas cumprem extensas jornadas de trabalho, para além de qualquer regulamentação, quando esta existe. As mais longas são, com frequência, as das trabalhadoras que dormem no local de trabalho. No outro extremo, as diaristas trabalham intensamente no seu dia de serviço, mas apenas uma fração consegue ocupar-se durante todos os dias das semanas do mês, o que resulta em remuneração ainda mais insuficiente.

As tarefas domésticas implicam o manuseio de produtos químicos, fogo, riscos (como altura, por exemplo), eletricidade - a exposição a fatores de risco de acidentes de trabalho conta com escassa compreensão dos empregadores e também das trabalhadoras, aumentando os riscos. Em situação de flagrante desrespeito aos direitos humanos e do trabalho, o trabalho doméstico também apresenta altos níveis de assédio sexual e moral.

Esses fatores, conjugados à própria situação de trabalho, incompatíveis com o pleno desenvolvimento das crianças, fizeram com que o trabalho infantil doméstico fosse integrado à lista das piores formas de trabalho infantil no Brasil, por meio do Decreto $n^{\circ} 6.481$, de 12 de junho de 2008. Embora o país conte com resultados importantes na redução do trabalho das crianças, estimativas recentes apontam, ainda, para um universo de aproximadamente 190 mil meninas nessa condição.

\footnotetext{
"Monica Cabañas GUIMARÃES, 2008.
} 


\section{Por que o trabalho doméstico é parte da economia informal?}

O trabalho doméstico é classificado como parte da economia informal. Mais do que por uma correspondência direta com os diferentes conceitos de informalidade, essa modalidade de ocupação parece estar assim classificada pela dificuldade em incluí-la nas definições correntes do trabalho e do mercado de trabalho, pois estas ainda não incorporam a esfera da reprodução como criadora de valor. Não é, pois, a precariedade (real) do trabalho doméstico que o define como informal, mas o lugar que ocupa na concepção tradicional do que é uma atividade econômica.

O trabalho doméstico remunerado é o pagamento a uma pessoa pela realização de uma ampla gama de tarefas necessárias à manutenção e reprodução da vida, o que engloba também o que a teoria denomina de reprodução da força de trabalho, embora não se reduza a isso. O trabalho doméstico não gera produtos ou serviços diretamente para o mercado, mas gera e mantém (reproduz) a força de trabalho que será vendida no mercado de trabalho. Dito de maneira direta: não haverá trabalhadores e trabalhadoras para apresentar-se ao trabalho e retornar a ele caso o trabalho doméstico não seja realizado. Isso convida a algumas reflexões sobre o lugar conceitual do trabalho doméstico remunerado e sobre sua regulamentação como um trabalho assalariado, tal como os demais postos assalariados da economia ou como uma prestação de serviços autônoma.

O trabalho doméstico é considerado informal porque seu local de realização é o domicílio em sua função reprodutiva, ou seja, não geradora de lucro, segundo a definição clássica. É por isso que a ampla conceituação de economia informal adotada pela OIT, em 2003 (na 17 $7^{a}$ Conferência Internacional de Estatísticos do Trabalho), que define a informalidade através da combinação das características do posto de trabalho e das unidades de produção, pôde abranger também o trabalho doméstico. Essa definição inclui entre as unidades de produção também os domicílios que produzem para o próprio consumo e aqueles que empregam trabalhadores domésticos remunerados, ou seja, o trabalho doméstico cabe na ampla definição de 2003, mas não é definido por ela - é a presença do trabalho doméstico em um domicílio que o insere na economia informal.

Há uma diferença entre os domicílios como espaço de produção de bens e serviços para o mercado e os domicílios como espaço de cuidado e de reprodução da força de trabalho, mas certamente esse é um ponto complexo. Os domicílios não são empresas, são espaços privados onde as trabalhadoras domésticas realizam seu trabalho (embora seu ofício seja público, não privado, visto que elas vendem sua força de trabalho nesse mercado de trabalho). O fato de os domicílios serem diferentes das empresas foi, no entanto, um dos argumentos para que a Justiça do Trabalho recusasse uma experiência pioneira de negociação coletiva no país, não reconhecendo a validade do acordo coletivo firmado entre o Sindicato das Trabalhadoras Domésticas de Campinas (SP) e uma associação de empregadoras local em 2003. ${ }^{12}$ Ainda não existe enquadramento produtivo e sindical adequado para essa categoria de trabalhadoras na atual legislação, na medida em que o trabalho doméstico não é considerado uma categoria produtiva.

Embora os/as trabalhadores/as realizem suas tarefas de cuidado em uma esfera privada dos indivíduos e das famílias, essa pode ser considerada uma esfera privada para as trabalhadoras? De seu ponto de vista, é um local de trabalho no qual as condições adequadas de exercício de suas funções devem necessariamente ser consideradas.

12 ORGANIZAÇÃO INTERNACIONAL DO TRABALHO, 2009. 


\section{Trabalho doméstico e família: quem cuida da culdadora?}

O trabalho doméstico é o encontro da esfera pública (como trabalho remunerado) com a esfera privada (o domicílio). Do ponto de vista da sociedade, supre as deficiências dos equipamentos sociais, especialmente nos países em que as redes de proteção social e os equipamentos públicos são precários. É por isso que as mulheres podem lançar-se ao trabalho remunerado fora do domicílio: outras mulheres virão para desempenhar as tarefas de cuidado a seu cargo. Esse repasse de tarefas, no entanto, encontra seu ponto final e seu beco sem saída, em grande parte dos casos, nas próprias trabalhadoras domésticas. É delas que a precariedade dos equipamentos públicos cobra o preço, pois são as que não têm a quem repassar essas tarefas para que possam ganhar seu sustento: quem cuida dos/ as filhos/as das trabalhadoras domésticas enquanto elas cuidam dos domicílios de outros? A tarefa doméstica nos lares dessas trabalhadoras é repassada para a família estendida (quando há), as filhas (da mais velha em diante) e os filhos, as redes de ajuda mútua (quando disponíveis), para a própria trabalhadora em sua jornada extenuante após o trabalho. Na maioria dos casos e países, em especial nos países pobres ou em desenvolvimento, o papel da rede pública de apoio é essencial, porém pouco efetivo, dada sua carência de oferta, adequação e qualidade.

O trabalho doméstico remunerado também tem efeitos que amenizam as tensões da desigual divisão das tarefas domésticas no interior das famílias. Ainda hoje, como mostram as pesquisas de uso do tempo em escala mundial, as tarefas domésticas continuam a ser majoritariamente responsabilidade das mulheres, especialmente quando há crianças pequenas. Assim, o mais importante formato de solução privada para a conciliação entre o trabalho fora do domicílio e as responsabilidades familiares nos países desenvolvidos e em desenvolvimento é, sem dúvida, a contratação de uma trabalhadora doméstica. ${ }^{13}$ Nas famílias que dispõem dos serviços das trabalhadoras domésticas remuneradas, a negociação da divisão das tarefas pode ser mais branda entre os casais ou entre o conjunto de habitantes, uma vez que o peso maior será sempre encargo da pessoa contratada. As tarefas domésticas também têm uma parte voltada ao cuidado - de crianças, de idosos e de doentes - que não é somente trabalho físico, mas principalmente atenção e tempo. Muitas vezes, essas atividades afetivas estão também a cargo das trabalhadoras domésticas ou a sua presença no domicílio libera os moradores para seu usufruto.

O trabalho doméstico - remunerado ou não - parece natural: não é entendido como trabalho, porque reproduz o cuidado feminino. Não gera valor porque não visa ao mercado. Não produz lucro. Definido sempre pela negativa e realizado em um tempo inexistente, como bem apontaram Betânia Ávila, Carmen Silva e Verônica Ferreira, ${ }^{14}$ permanece invisível. O trabalho doméstico é, no entanto, uma das mais antigas e significativas ocupações das mulheres no mundo, e o cuidado com o domicílio - não importa quem o faça - é indispensável para os indivíduos e as famílias e para o funcionamento geral da economia. Por essa razão, o pensamento feminista e os movimentos de mulheres passaram a questionar alguns dos cânones correntes, buscando perspectivas teóricas e explicativas que dessem conta do universo feminino, perguntando-se por que a geração de valor é restrita à produção para o mercado, uma vez que a reprodução é um bem colocado continuamente à disposição desse mesmo mercado. ${ }^{15} \mathrm{O}$ trabalho doméstico - remunerado ou não - mostra

\footnotetext{
${ }^{13}$ FLORO E MEURS apud ORGANIZAÇÃO INTERNACIONAL DEL TRABAJO E PROGRAMA DE LAS NACIONES UNIDAS PARA EL DESAROLLO, 2009.

${ }^{14}$ Betânia ÁVILA, Carmen SILVA e Verônica FERREIRA, 2005.

${ }^{15}$ A esse respeito, ver Hildete Pereira MELO, Claudio Monteiro CONSIDERA e Alberto DI SABBATO, 2005.
} 
a contradição presente na visão dicotômica da geração de valor no capitalismo e na organização patriarcal da sociedade, que separa em dois mundos - um visível e outro invisível - o público e o privado, a produção e a reprodução.

\section{Desafios para o trabalho decente}

O trabalho doméstico é, por todas as razões mencionadas e por muitas outras que este artigo não tem a pretensão de esgotar, um grande desafio. Considerá-lo com a seriedade e a profundidade que exige - por sua importância, pelo enorme contingente de pessoas que envolve e pelo lugar estratégico que ocupa na vida dos indivíduos, das famílias e da economia em todo o mundo - implica rever e reordenar concepções de mundo e da organização social, preceitos e normativas jurídicas, relações sociais, políticas públicas e ações das organizações da sociedade. Implica construir um esforço em nível mundial e nos espaços regionais e nacionais para a consecução de ações e políticas que possam transformar o quadro atual.

Com essa perspectiva, a OIT irá iniciar a discussão de um instrumento internacional de proteção aos/às trabalhadores/as domésticos/as em sua próxima Conferência Internacional do Trabalho, em 2010, que poderá tomar a forma de uma convenção ou de uma recomendação. O diagnóstico da OIT aponta o trabalho doméstico como o mais desprotegido de todos e que, "ainda que os direitos e princípios fundamentais do trabalho apliquem-se a todos os trabalhadores e trabalhadoras, incluindo os domésticos, os déficits de trabalho decente que afetam esta categoria são manifestos". ${ }^{16}$ Também ressalta as iniciativas tomadas em muitos países, que vêm criando ou preparando a adoção de leis e políticas públicas nesse âmbito.

A elaboração e a aprovação de um instrumento de proteção internacional da OIT, seja uma convenção, uma recomendação ou outra modalidade, passam por várias etapas, conforme a regulamentação da Organização. As primeiras - de proposição e aprovação do tema como pauta da Conferência - já foram cumpridas. Também já foi elaborado o relatório Trabalho Decente para os Trabalhadores Domésticos, ${ }^{17}$ destinado a subsidiar os constituintes. Esse relatório inclui um questionário a ser respondido pelos mandantes da OIT (organizações de trabalhadores e empregadores e governos), e os resultados dessa consulta serão apresentados em 2010. Com base nessas informações e nos debates realizados na ocasião, será, então, definido o formato que o instrumento deverá tomar. Seja qual for o formato decidido, seu conteúdo será preparado ao longo do ano de 2010 para posterior discussão e aprovação na Conferência de 2011.

Para preparar a resposta ao questionário por parte das organizações de trabalhadoras domésticas e também definir as estratégias a serem adotadas, a Federação Nacional das Trabalhadoras Domésticas (FENATRAD) e os sindicatos realizaram no mês de agosto, em Brasília, um seminário que contou com a participação de aproximadamente 40 dirigentes sindicais domésticas e também de trabalhadoras domésticas da Guatemala, da Bolívia e do Paraguai como observadoras, em uma iniciativa do Fundo de Desenvolvimento das Nações Unidas para a Mulher (UNIFEM) e da OIT, com o apoio da Secretaria Especial de Políticas para as Mulheres (SPM), da Secretaria Especial de Políticas de Promoção da Igualdade Social (SEPPIR) e do Centro Feminista de Estudos e Assessoria (CFÊMEA). É importante ressaltar que também o governo brasileiro e as centrais sindicais enviaram resposta ao questionário para a OIT.

16 ORGANIZAÇÃO INTERNACIONAL DO TRABALHO, 2008, p. 16, tradução nossa.

17 ORGANIZAÇÃO INTERNACIONAL DO TRABALHO, 2009. 
Todo esse esforço, nos países e em nível mundial, tem como ponto de partida a convicção de que a falta de reconhecimento e de proteção social que penalizam o trabalho doméstico constitui um impedimento para o objetivo de alcançar um trabalho decente para todos os homens e mulheres.

É muito importante trazer o emprego doméstico para fora de sua invisibilidade e desvalorização e situá-lo na categoria de uma profissão, um trabalho aprendido e com requisitos próprios. Desnaturalizá-lo para fazer valer, também para essa forma de prover o próprio sustento, as mesmas noções e princípios que integram as demais ocupações existentes no mercado de trabalho. Além disso, prover de políticas e de ações sociais aqueles/as que o exercem para criar-Ihes as condições de exercício da cidadania plena e de superar a pobreza e as más condições de vida e trabalho.

Nesse sentido, os princípios e direitos fundamentais do trabalho que sustentam a noção de trabalho decente são um patamar básico e, ao mesmo tempo, uma meta importante para o trabalho doméstico no Brasil e no mundo. Embora ele se aplique a muitas outras situações no mercado de trabalho, é certo que sua aplicação ao trabalho doméstico traria uma profunda, justa e necessária mudança para milhões de trabalhadoras e trabalhadores.

\section{Referências bibliográficas}

ÁVILA, Maria Betânia et al. (Orgs.). Reflexões feministas sobre informalidade e trabalho doméstico. Recife: SOS Corpo - Instituto Feminista para a Democracia, 2008.

ÁVILA, Maria Betânia; SILVA, Carmen; FERREIRA, Verônica (Orgs.). Mulher e trabalho. Recife: SOS Corpo - Instituto Feminista para a Democracia; São Paulo: Secretaria Nacional sobre a Mulher Trabalhadora da CUT, 2005.

COSTANZI, Rogerio Nagamine; RIBEIRO, Helio Vinicius Moreira. A difícil luta pelos direitos trabalhistas dos trabalhadores domésticos. Texto apresentado à ABET em 2007. Mimeografado.

DIEESE. Medida Provisória 284: impactos para empregados domésticos e para empregadores. São Paulo: DIEESE, jul. 2006. Nota Técnica nº 27.

GUIMARÃES, Monica Cabañas. Políticas para a expansão da cobertura dos trabalhadores em setembro 2005. Brasília: MPS, 2008. Textos para discussão n 177 - Trabalhadoras domésticas: a experiência do Brasil.

IBGE. Tempo, trabalho e afazeres domésticos. Rio de Janeiro: IBGE, 2007.

MELO, Hildete Pereira; CONSIDERA, Claudio Monteiro; DI SABBATO, Alberto. Os afazeres domésticos contam. Rio de Janeiro: Universidade Federal Fluminense, 2005.

ORGANIZAÇÃO INTERNACIONAL DO TRABALHO. $17^{a}$ Conferencia Internacional de Estadísticos del Trabajo. Ginebra, 24 de noviembre a 3 de diciembre de 2003. Informe I - Informe general. Ginebra: OIT, 2003.

ORGANIZAÇÃO INTERNACIONAL DO TRABALHO. Decent Work and Poverty Reduction Strategies. Geneva: ILO, 2007.

. Fecha, lugar y orden del día de la 99a Reunión (2010) de la Conferencia Internacional del Trabajo. Consejo de Administración. Ginebra: OIT, 2008.

. Conferencia internacional del trabajo, 99a Reunión (2010). Informe IV (1) - Trabajo decente para los trabajadores domésticos. Ginebra: OIT, 2009.

ORGANIZAÇÃO INTERNACIONAL DO TRABALHO; PROGRAMA DAS NAÇÕES UNIDAS PARA O DESENVOLVIMENTO. Trabalho e família: rumo a novas formas de conciliação com corresponsabilidade social. Brasília: OIT; PNUD; Secretaria Especial de Políticas para as Mulheres, 2009. 
ORGANIZAÇÃO INTERNACIONAL DEL TRABAJO; PROGRAMA DE LAS NACIONES UNIDAS PARA EL DESAROLLO. Trabajo y família: hacia nuevas formas de conciliación con co-responsabilidad social. Santiago: OIT; PNUD, 2009.

PINHEIRO, Luana et al. Retrato das desigualdades de gênero e raça. 3. ed. Brasília: Ipea; SPM: UNIFEM, 2008.

SANCHES, Solange. O trabalho doméstico no Brasil. Brasília: OIT, 2006. No prelo.

SECRETARIA ESPECIAL DE POLÍTICAS PARA AS MULHERES et al. A crise econômica internacional e os (possíveis) impactos sobre a vida das mulheres. SPM: Brasília, 2009. (Boletim Mulher e Trabalho).

\section{Domestic Work: Challenges for Decent Work}

Abstract: This article presents an overview of the situation of the domestic workers and focuses on some issues related to its dimension in the world and in Brazil, to their conditions of work and its importance to the labor market and to the households. We aim to demonstrate the relevance of the concept of decent work, promoted by ILO - International Labor Organization, for the domestic work and the need to extend their rights to level them with the other workers. It also highlights the opportunity offered by the next International Labor Conference, in 2010, when one of the issues of the agenda is to discuss the crafting and adoption of international labor standards in the form of a specific convention or recommendation.

Key Words: Domestic Work; Decent Work; Conditions of Work; Gender; Equality. 